\title{
Sistem Pembangkit Listrik Tenaga Surya untuk Tanaman Hidroponik
}

\author{
David Setiawan ${ }^{1}$, Hamzah Eteruddin ${ }^{2}$, Latifa Siswati ${ }^{3}$ \\ ${ }^{12}$ Prodi Teknik Elektro, Fakultas Teknik, Universitas Lancang Kuning \\ ${ }^{3}$ Prodi Agribisnis, Fakultas Pertanian, Universitas Lancang Kuning \\ eMail : dsetia@unilak.ac.id, hamzah@unilak.ac.id, latifa@unilak.ac.id
}

\begin{abstract}
ABSTRAK
Maraknya menanam tanaman dengan cara Hidroponik saat ini, banyak digemari karena tidak memerlukan tanah dan lahan yang luas. Dengan menanam dengan cara hidroponik, hasil panen akan lebih cepat namun perlu untuk memperhatikan ketepatan dalam pemberian nutrisi, intensitas cahaya dan suhu sekitar tanaman. Menanam hidroponik menggunakan metode NFT (Nutrient Film Technique) dibutuhkan aliran air yang tetap terjaga, tujuannya untuk mengalirkan air nutrisi pada akar tanaman. Dalam praktiknya, PLN digunakan untuk menghidupkan pompa air tersebut namun bila suplai energi dari PLN mati akibat gangguan atau kealpaan maka pasokan nutrisi tanaman juga akan ikut terhenti sehingga diperlukan suatu solusi. Dalam penelitian ini, penulis akan membuat desain sistem pembangkit Tenaga Surya (Panel Surya) serta sistem kendali terhadap aliran air yang akan memasok nutrisi ke tanaman hidroponik tersebut.
\end{abstract}

Kata kunci: Hidroponik, Panel Surya, Pompa Air, Nutrisi dan Oksigen, Tanaman

\begin{abstract}
The rise of planting plants using the hydroponics method is currently popular because it does not require extensive land and land. By planting hydroponically, yields will be faster but it is necessary to pay attention to the accuracy in providing nutrition, light intensity and temperature around the plant. Hydroponics planting using the NFT (Nutrient Film Technique) method requires a maintained water flow, the aim is to drain nutrient water to the plant roots. In practice, PLN is used to turn on the water pump, but if the energy supply from PLN turns off due to a disturbance or neglect, the plant's nutrient supply will also stop, so a solution is needed. In this study, the authors will design a solar power generating system (Solar Panel) and a control system for water flow that will supply nutrients to the hydroponic plants.
\end{abstract}

Keywords: Hydroponics, Pumps, Solar Panels, Nutrition and Oxygen, Plants

\section{PENDAHULUAN}

Dimasa pandemi seperti saat ini, ramai ibu-ibu menanam bunga, dan banyak juga menanam sayur menggunakan cara hidroponik, menanam sayur dengan cara hidroponik tidak membutuhkan lahan yang luas sehingga cocok dibuat pada pekarangan yang relatif sempit, kita bisa menanam di mana pun dengan cara menanam hidroponik. Menanam menggunakan cara hidroponik, hasil panen akan relatif lebih cepat. Namun perlu diperhatikan beberapa aspek dalam pemeliharaannya, yaitu : nutri yang diberikan haruslah tepat, pencahayaan dan suhu juga harus diperhatikan serta pompa air yang mengalirkan oksigen dan nutri pada air harus dijaga. Menanam dengan hidroponik memerlukan nutrisi yang tepat yang disalurkan air pada akar tanaman.

Menanam tanaman menggunakan cara NFT memerlukan pompa air agar nutrisi yang mengalir bersama air dapat dialirkan ke akar-akar tanaman. Sementara 
tanaman menggunakan cara WICK tidak memerlukan pompa air. Menanam menggunakan cara NFT adalah cara paling popular, dan suplai nutrisi terletak pada air maka diperlukan perputaran air / aliran air agar nutrisi dan oksigen yang dibutuhkan akar dapat disuplai. Bayangkan bila kita lupa menghidupkan pompa atau terjadi pemadaman bergilir/gangguan listrik PLN, maka tanaman yang membutuhkan nutrisi dan oksigen akan lagu dan mati atau tidak berkembang, maka diperlukan suatu solusi agar pencinta tanaman hidroponik yang menggunakan cara NFT tetap berkreasi tanpa memiliki kekhawatiran akan permasalan diatas.

Dalam penelitian ini, penulis akan memberikan suatu solusi yaitu desain pembangkit listrik bertenaga cahaya matahari (panel surya) untuk tanaman hidroponik menggunakan cara NFT. Diharapkan, desain ini dapat memberikan kontribusu dan manfaat terutama bagi pecinta tanaman hidroponik.

\section{TINJAUAN PUSTAKA}

\subsection{Tanaman Hidroponik}

Istilah hidroponik digunakan untuk bercocok tanam tanpa menggunakan tanah sebagai media tumbuhnya. Tanaman hidroponik dapat tumbuh dengan dengan menjaga aliran air yang membawa oksigen dan nutrisi ke akar tanaman.

Bercocok tanam dengan cara hidroponik relatif lebih cepat berkembang karena memiliki beberapa kelebihan. Kelebihan dalam bercocok tanaman menggunakan cara hidroponik lebih terjamin dalam pertumbuhan dan berproduksinya serta perawatan yang lebih mudah, penggunaan pupuk yang lebih hemat dan juga tidak kotor. Kemudian kontinuitas hasilnya lebih jelas karena tidak memiliki musim tanam (Lingga, 2005).

Tanaman yang dapat ditanaman atau dibudidayakan dengan cara menanam hidroponik atau sistem terapung berupa sayuran yang tidak berat seperti pakchoy, selada, kangkung, kailan dan sawi-sawian yang lain (Sutiyoso, 2006). Untuk memenuhi unsur hara atau zat makanan untuk pertumbuhan tanaman, kita dapat mencampurkan atau melarutkan ke dalam air campuran pupuk organik. Pupuk yang dicampur ini bisa diperoleh atau dibuat dari ramuan sendiri seperti garam mineral dengan menggunakan formulasi yang telah ditentukan atau menggunakan pupuk buatan yang sudah siap pakai.

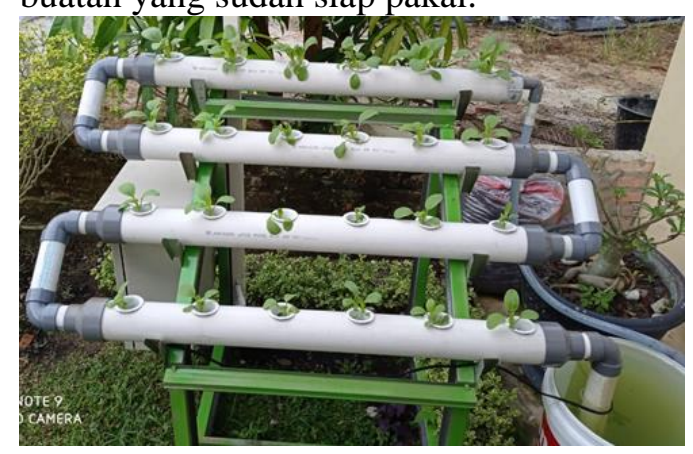

Gambar 1. Tanaman Hidroponik

\subsection{Motor Listrik sebagai Pompa Air}

Motor listrik yang digunakan untuk pompa air merupakan alat untuk energi listrik menjadi energi mekanik, energi mekanik tersebut digunakan untuk memutar atau memompompa air ke tanaman hidroponik. Secara umum, prinsip kerja motor listrik sebagai berikut :

1. Jika medan magnet dialiri arus listrik maka akan menghasilkan gaya, begitu juga jika belitan berupa lingkaran yang dialiri asur maka akan ada gaya pada arah satu ke arah lainnya atau dari kanan medan magnet akan mendapatkan gaya pada arah yang berlawanan.

2. Kumparan akan berputar dari pasangan gaya yang dihasilkan oleh torque atau putar.

3. Ada beberapa loop pada dinamo motor-motor listrik untuk memberikan tenaga putaran yang lebih seragam dan medan magnetnya dihasilkan oleh susunan elektromagnetik yang disebut kumparan medan.

Beban motor pada motor listrik atau pompa air berupa keluaran tenaga putar sesuai dengan kecepatan yang diinginkan atau diperlukan. Ada tiga kelompok beban yang umum pada motor listrik (BEE India, 2004) :

1. Beban torque disebut konstan jika beban mendapat permintaan keluaran energinya bervariasi dengan kecepatan operasinya namun torque nya tidak bervariasi. Contohnya rotary kilns, 
conveyors dan pompa displacement konstan disebut beban dengan torque konstan.

2. Beban dengan variabel torque adalah beban dengan torque yang bervariasi dengan kecepatan operasi, seperti fan (torque bervariasi sebagai kwadrat kecepatan) dan pompa sentrifugal adalah contoh dari beban dengan variabel torque.

3. Beban dengan energi konstan adalah beban dengan permintaan torque yang berubah dan berbanding terbalik dengan kecepatan, seperti peralatanperalatan mesin adalah contoh beban dengan daya konstan.

Berikut prinsip kerja dari motor listrik :

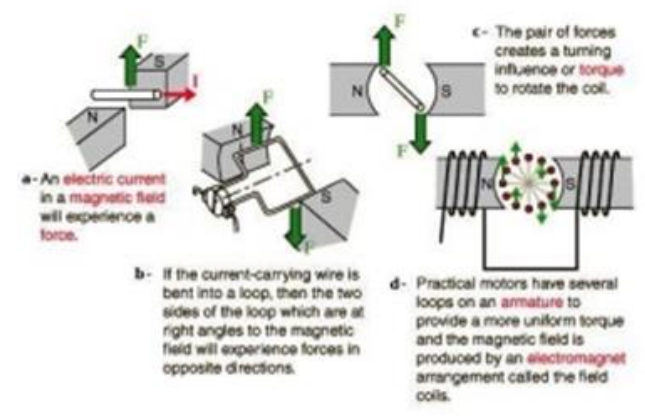

Gambar 2. Prinsip Kerja Motor Listrik

\subsection{Panel Surya}

Ada beberapa metode untuk menghasilkan listrik. Salah satunya adalah efek fotovoltaik (wikipedia.org), efek fotovoltaik adalah metode yang paling populer digunakan untuk menghasilkan listrik. Efek fotovoltaik bekerja dengan mengubah energi matahari menjadi arus listrik. Banyak para ilmuwan mengembangkan efek tofovoltaik atau yang dikenal dengan nama panel surya dimana energi cahaya dikonversi menjadi energi listrik melaui hukum kekekalan energi. Panel surya yang terdiri dari sel surya dapat digunakan untuk mengubah cahaya menjadi listrik. Dalam pemeliharaannya, sel surya perlu di dilindungi dari kerusakan dan kelembaban mungkin saja terjadi. Pemeliharaan panel surya sangat diperlukan dalam rangka agar tidak merusak efisiensi panel surya secara signifikan, agar tidak menurunkan masa pakainya tidak pendek. Panel surya umumnya memiliki umur sekitar 20 tahun, dalam jangka waktu tersebut pemakaian panel surya tidak akan mengalami penurunan efisiensi yang signifikan. Dalamkemajuan teknologi, banyak panel surya yang dijual dan memiliki efisiensi rata-rata $15 \%$, sangat jarang dijumpai efisiensinya melebih dari $20 \%$

Dalam penggunaan panel surya pada tanaman hidroponik selain hemat energi karena sumber energi dari matahari, panel surya juga tidak memancarkan emisi gas rumah kaca yang sangat berbahaya jika dibandingkan dengan pembakaran bahan bakar dari bahan baku fosil. Penggunaan panel surya ini dapat memberikan kontribusi terhadap dampak perubahan iklim, sehingga penggunaan panel surya pada tanaman hidroponik dapat memberikan kontribusi untuk mendapatkan udara bersih dan energi bersih dari sumber energi yang paling berlimpah di planet bumi, yaitu matahari..

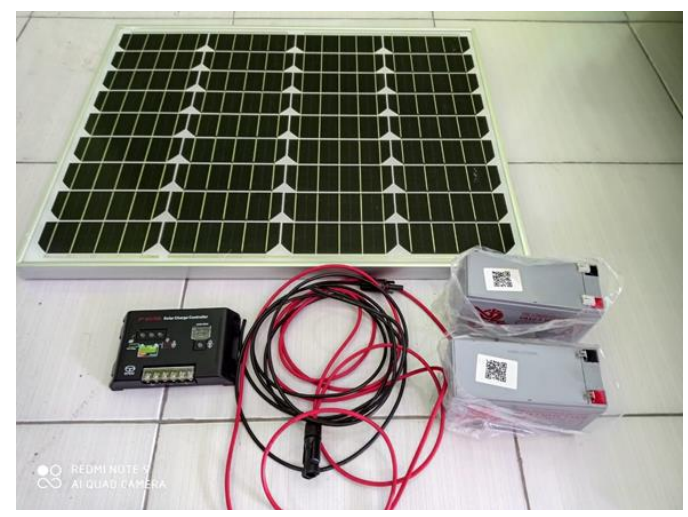

Gambar 3. Panel Surya, Charge Controler dan Battery

Ada beberapa keunggulan dan kelemahan dalam menggunakan panel surya, berikut ini keunggulan dalam penggunaan Panel Surya :

1. Panel surya termasuk ramah lingkungan karena tidak memancarkan emisi gas rumah kaca yang berbahaya, seperti karbon dioksida. Panel surya juga tidak memberikan kontribusi terhadap perubahan iklim.

2. Panel surya memanfaatkan energi matahari, dan matahari adalah sumber energi yang paling berlimpah di planet bumi. 
3. Panel surya berbiaya perawatan atau pemeliharaan yang sangat rendah serta mudah dipasang.

4. Dibeberapa negara, pemilik rumah yang menggunakan panel surya mendapat insentif yang menguntungkan bagi pemilik rumah itu sendiri.

5. Efisiensi masa pakai panel surya umumnya selama 20 tahun sehingga tidak kehilangan banyak efisiensi dalam masa pakai tersebut.

6. Karena efisiensi diatas 20 tahun, secara otomatis penggunaan panel surya memberikan menggaransi bagi penggunanya dalam penghematan penggunaan biaya listrik / energi.

Sedangkan kelemahan dalam menggunakan panel surya adalah :

1. Walaupun beberapa pabril panel surya telah menurunkan harga namun secara umum harga panel surya masih relatif mahal.

2. Salah satu penyebab alasan orang tidak menggunakan panel surya adalah karena efisiensi paner surya rata-rata kurang dari 20\% sehingga efisiensi panel surya masih perlu untuk ditingkatkan lagi secara signifikan, walaupun begitu sumber energi dari matahari adalah sumber energi gratis yang disediakan alam untuk kita.

3. Bahan yang digunakan dalam pembuatan panel surya terbuat dari beberapa bahan yang tidak ramah lingkungan, seperti material silikon.

4. Limbah panel surya jika tidak berhatihati dalam mendaur ulang panel surya akan menyebabkan kerusakan pada lingkungan sekitarnya, karena limbah yang dihasilkan memiliki kandungan selenium, silikon dan lainnya sehingga kandungan-kandungan tersebut merupakan gas rumah kaca yang ada pada panel surya.

\section{HASIL DAN PEMBAHASAN}

Desain yang akan akan dibahas dalam penelitian adalah analisa kebutuhan daya listrik untuk pompa air hidroponik terhadap pemilihan panel surya dan baterai sehingga energy yang dihasilkan dapat mencukupi suplai energi ke memonpa air sebagai penyalur air dan nutrisi bagi tanaman hidroponik. Adapun beberapa desain yang akan di cobakan adalah :

1. Sistem Panel Surya tanpa Baterai

Panel surya sebagai pembangkit tenaga matahari akan menghasilkan keluaran berupa tegangan DC. Tegangan DC tersebut dapat di hubungkan ke beban seperti motor listrik DC atau pompa air, namun tegangan yang dihasilkan panel surya yang tidak stabil dapat mempengaruhi kinerja motor bahkan kerusakan terhadap motor listrik. Untuk mengatasinya, dibutuhkan rangkaian pengendali keluaran sehingga tegangan keluaran menjadi tetap.

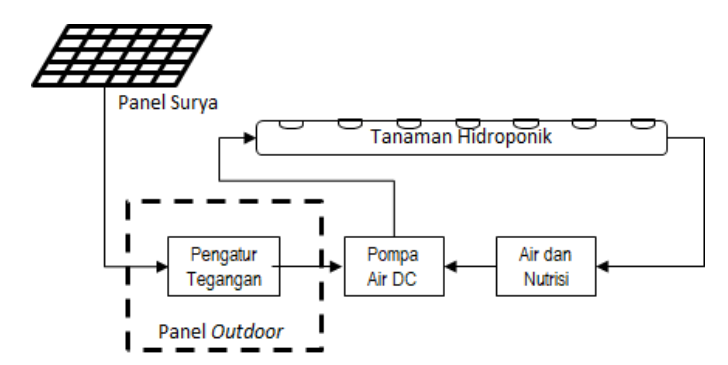

Gambar 4. Sistem Tanaman Hidroponik Panel Surya Tanpa Baterai

Kelemahan dari sistem diatas adalah motor DC sebagai pompa air hanya dapat menyuplai air dan nutrisi pada waktu panel surya menerima cahaya dari matahari sehingga pada saat gelap, nutrisi dan air tidak mengalir ke tanaman hidroponik.

\section{Sistem Panel Surya menggunakan Baterai}

Untuk mengatasi permasalahan diatas, dibutuhkan penyimpanan energi yang dihasilkan oleh panel surya. Dalam menimpan energi dari panel surya, tegangan yang akan diberikan kepada penyimpan energi berupa baterai atau aki tersebut tidak boleh terlalu besar agar aki bisa bertahan lama atau tidak cepat rusak, dan sebaliknya juga tidak akan dapat menyimpan energi bilamana tegangan yang diberikan lebih kecil darpipada tegangan aki tersebut sehingga dibutuhkan rangkaian pengontrol 
penyimpanan energi ke aki atau charge controler.

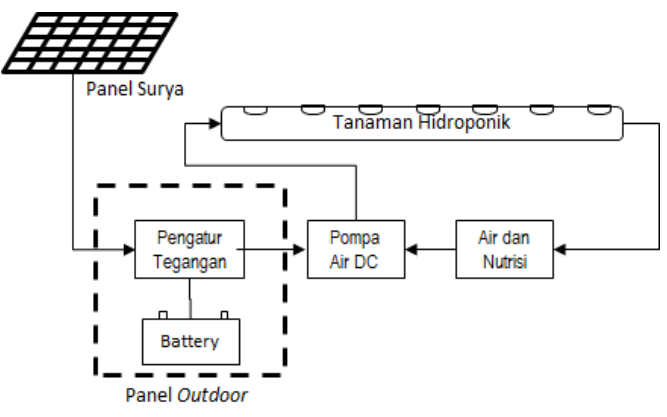

Gambar 5. Sistem Tanaman

Hidroponik Panel Surya Menggunakan

Baterai

Kelemahan dari sistem diatas adalah tidak adanya sistem pengaman, pengaman terhadap hubung singkat di panel surya atau pun hubung singkat di motor DC. Hubung singkat dapat mengakibatkan kerusakan terhadap panel surya dan sistem / rangkaian pengatur tegangan /charge controler.

3. Sistem Panel Surya menggunakan PMT

PMT atau singkatan dari pemutus dapat berupa fuse atau sekring dan dapat pula berbentuk mini switch breaker atau MCB. PMT tersebut akan trik atau putus bilamana terjadi hubung singkat untuk menjaga sistem dibawahnya dari kerusakan akibat hubung singkat.

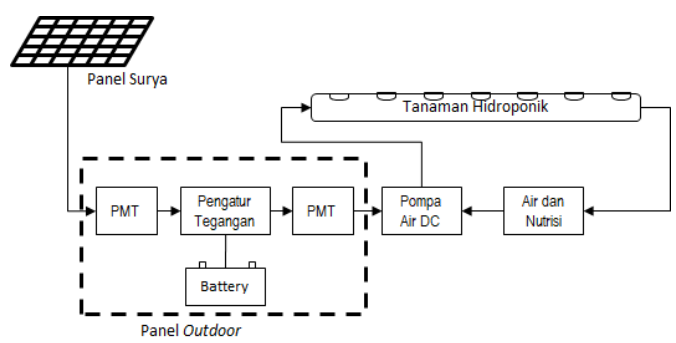

Gambar 6. Sistem Tanaman

Hidroponik Panel Surya Menggunakan PMT

Kelemahan dari sistem ini terletak pada motor DC, motor DC umumnya tidak dapat hidup terus menerus atau desain pompa air dari motor DC dedesain untuk pompa yang bersifat tidak dapat terus menerus dihidupkan, sedangkan pompa air AC yang digunakan untuk pompa air aquarium dapat dihidupkan secara terus menerus sehingga dibutuhkan inverter yang merubah tegangan DC menjadi tegangan AC.

4. Sistem Panel Surya menggunakan Inverter DC ke AC

Sistem panel surya menggunakan inverter adalah sistem tanaman hidroponik yang mudah digunakan oleh pengguna karena keluaran tegangannya sudah berupa tegangan AC sehingga pengguna dapat menghubungi pompa air untuk hidroponik yang banyak dijual dipasaran.

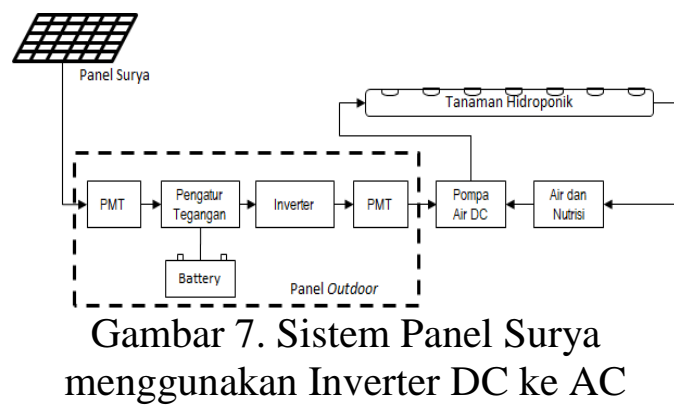

Dalam penerapannya, inverter yang digunakan harus menghasilkan keluaran berupa tegangan sinus murni agar motor sebagai pompa air tidak cepat rusak. 


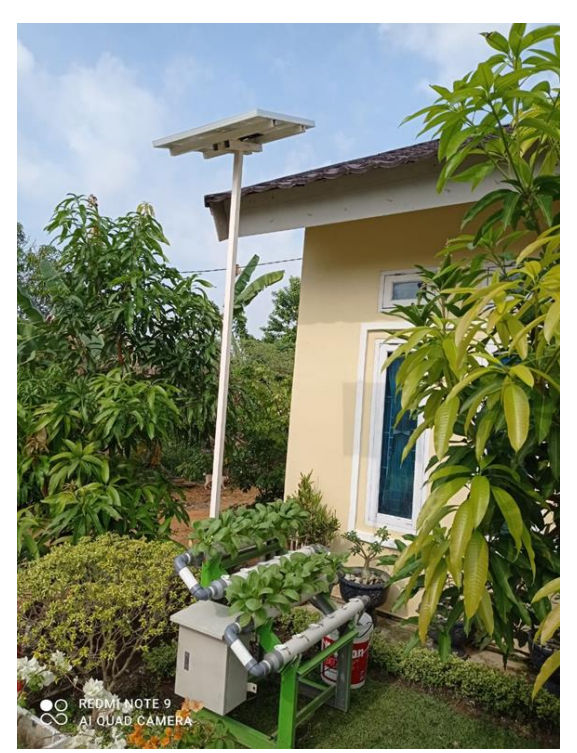

Gambar 8. Sistem Tanaman Hidroponik Panel Surya

\section{ANALISA DESAIN HIDROPONIK PANEL SURYA}

1. Sistem Panel Surya tanpa Baterai

Dalam pengujian, awalnya digunakan desain 1 dimana panel surya setelah charge controler langsung dihubungkan ke pompa air. Pompa air yang digunakan dalam tahapan ini adalah pompa air DC. Pompa air bekerja mulai dari jam 6:45pagi sampai dengan jam 18:10 sore.

Kuat dan lemahnya aliran air tergantung pada intensitas cahaya, saat mendung terjadi, pompa air nyaris lemah dan tidak beroperasi. Pola ini kurang direkomendasikan karena pompa air tidak stabil untuk mengaliri air yang membawa oksigen dan nutrisi ke tanaman.

2. Sistem Panel Surya menggunakan Baterai

Desain kedua lebioh baik dari desain pertama dimana pompa air lebih stabil dan dapat bekerja hingga malam hari. Kelemaham pada sistem kedua ini adalah sistem keaamanan peralatan yang tidak ada sehingga rangkaian dapat rusak jika terjadi hubung singkat dan panel surya juga dapat rusak jika terjadi hubungsingkat pada rangkaian dan instalasinya. Hubung singkat bisa terjadi akibat terkelupasnya isolasi kabel maupun masalah lingkungan lainnya.

3. Sistem Panel Surya menggunakan PMT

Desain ketiga ini adalah desain yang lebih baik dari desain kedua, namun dalam pengujiannya, motor DC tidak dapat beroperasi secara terus menerus, 2 pompa air DC megalami kerusakan saat percobaan dilakukan untuk memompa air secara terus menerus.

4. Sistem Panel Surya menggunakan Inverter DC ke AC

Penggunaan pompa air aquarium sebagai pompa air untuk mengalirkan oksigen dan nutrisi pada tanaman hidroponik dirasa lebih baik dibandingkan motor DC sebagai pompa air pada tanaman hidroponik, sehingga diperlukan rangkaian converter dari tegangan DC yang dihasilkan panel surya menjadi tegangan AC dengan gelombang sinus murni agar motor AC sebagai pompa dapat bertahan lama / tidak cepat rusak.

\section{KESIMPULAN DAN SARAN}

5.1. Kesimpulan

1. Penggunaan panel surya pada tanaman hidroponik fleksibel untuk lakasi tanaman terbuka / dibawah sinar matahari.

2. Dalam penggunaan panel surya, penggunaan pompa air DC lebih ekonomis namun kelemahan motor DC umumnya tidak dapat operasikan secara terus menerus.

3. Motor AC atau pompa Aquarium yang dedesain untuk dapat beroperasi secara terus menerus dapat digunakan dengan menambah rangkaian inverter dengan gelombang output sinus murni.

\subsection{Saran}

Penggunaan motor DC untuk pompa air pada tanaman Hidroponik Panel Surya dapat menghemat biaya karena tidak diperlukannya rangkaian inverter serta aman dari sengatan listrik sehingga perlu 
dilakukan penelitian terhadap desain motor DC untuk pompa air yang dapat beroperasi terus menerus seperti pompa air aquarium yang umum dijual dipasaran.

\section{DAFTAR PUSTAKA}

Abdul Kadir, 2017, Dasar Raspberry $P i$, Andi Offset, Yogyakarta, ISBN: 978-979-29-5811-9

Affan Bachri, 2015, Analisis Efisiensi Pemakaian Daya Listrik Di Universitas Islam Lamongan, Jurnal Teknika Vol. 7 No.1, ISSN No. 2085-0859

David Setiawan, Usaha Situmeang, 2018, Evaluasi Sistem Penerangan Lampu Jalan Di Lingkungan Universitas Lancang Kuning.Jurnal Teknik Elektro Fakultas Teknik Universitas Lancang Kuning.

Deni Almanda, Krisdianto, Erwin Dermawan, 2014, Managemen Konsumsi Energi Listrik Dengan Menggunakan Sensor PIR dan LM 35, Jurnal Elektrum, Vol. 14 No. 1, ISSN : 1979-5564, e-ISSN : 2550-0678

Effendi, asnal. Asep Suryana. 2013. "Evaluasi Sistem Pencahayaan Lampu Jalan," 86-94.

Faizal Reza, Hartono, Siswanto Nurhadiono, 2015, Analisa Deviasi kWh Meter Memanfaatkan Aplikasi Android "App Tole", Jurnal Institusi Teknologi Dan Seni, Vol.7, No 3, ISSN: 19782497

Indrakoesoema Koes, Kiswanto, Muhammad Taufiq, 2013, Kajian Penghematan Energi Listrik Dengan Pemasangan Inverter Pada Motor Fan Menara Pendingin Rgs - Gas, Seminar Nasional VIII SDM Teknologi Nuklir, ISSN : 1978-0176

Irwan Dinata, Wahri Sunanda, 2015, Implementasi Wireless Monitoring Energi Listrik Berbasis Web
Database, Jurnal Nasional Teknik Elektro, Vol : 4, No. 1, ISSN: 2302-2949

Itmi Hidayat Kurniawan, Latiful Hayat, 2014, Perancangan Dan Implementasi Alat Ukur Tegangan,Arus Dan Frekuensi Listrik Arus Bolak-Balik Satu Fasa Berbasis Personal Computer, Techno Jurnal Vol.15 No.1, hal. 21-31 ISSN 1410 - 8607

Margioni Abdillah, 2014, Desain dan Instalasi Penerangan jalan Raya, Yayasan Kemajuan Teknik, Pontianak, ISBN: 978-602-727746-5

Panggih Sudarmono, Deendarlianto, Adhika Widyaparaga, 2018, Energy efficiency effect on the public street lighting by using LED light replacement and $k$ wh-meter installation at DKI Jakarta Province, Indonesia, Journal of Physics: Conf. Series 1022(2018) 012021 doi:10.1088/17426596/1022/1/012021

P.Van.Harten, E.Setiawan, 1985, Instalasi Listrik Arus Kuat 2, Trimitra Mandiri.

Sinaulan M. Olivia, Yaulie D. Y. Rindengan,Brave A. Sugiarso, 2015, Perancangan Alat Ukur Kecepatan Kendaraan Menggunakan ATMega 16, Jurnal Teknik Elektro dan Komputer, Vol 4, No 2, ISSN: 2301-8402

Siti Ahadaiah, Muharnis, Agustiawan, Implementasi Sensor PIR Pada Peralatan Elektronik Berbasis Microcontroller, Jurnal INOVTEK POLBENG, Vol: 01 No,1, ISSN:2088-6225 E-ISSN: 2580-2798

William Timotius, Muhammad Sofrodin, Suryono, 2014, Efisiensi Penerangan Jalan Umum Menggunakan Sensor Gerak Berbasis Mikrokontroler, Prosiding Seminar Nasional Sains 
dan Pendidikan Sains UKSW

Salatiga, Vol: 5, N0.1, ISSN : 2087-0922

Zubaili Isfarizky, Fardian, Alfatirta Mufti, 2017, Bangun Sistem Kontrol Pemakaian Listrik Secara Multi Channel Berbasis Arduino (Studi Kasus Kantor LBH Banda Aceh), JurnalTeknik Elektro,Fakultas Teknik Universitas Syiah Kualam Vol.0202 hal: 30-35 e-ISSN: 2252-7036

Zuriman Anthony, 2011, Penggunaan Kontaktor Sebagai Sistem Pengaman Motor 3 Phasa Terhadap Kehilangan 1-Phasa Sistem Tenaga, Jurnal Momentum Vol.11 No.2 ISSN: 1693 - 752X 